\title{
What Future for Organic Aquaculture?
}

\section{Antonino Nizza*}

Department of Animal Science and Food Control, University of Naples Federico II, Italy

\section{Origin, status and perspectives of a growing industry}

The origins of organic aquaculture are quite recent. The earliest records date back to the 90s when in Austria and Germany organic production systems for carp began to develop. In 1995, in Ireland, the German entrepreneur Udo Klütsch, the marine biologist and salmon farmer David Baird and the association Naturland of Germany, entered into a development partnership for producing organic salmon. Subsequently, the organic production of this species was also extended to England and France with good results. The success achieved in these countries accelerated the spread of organic aquaculture initiatives worldwide. An additional boost to organic aquaculture was given by the development of the organic production standards for shrimps in Ecuador in which once again Naturland association was involved. Beside these species, trout and arctic char in Europe and pangasius and tilapia in Asia were also reared using organic methods, while in Mediterranean countries sea bass and sea bream farms were converted to organic.

In the United States, discussions on organic aquaculture standards started in 1998 within the National Organic Standards Board. In 2000, IFOAM (International Federation of Organic Agriculture Movements) published a first draft of the basic regulations for organic aquaculture which was finally approved after five years. Recently, several scientific and cultural associations have begun to organize seminars, workshops and conferences to illustrate and promote organic aquaculture. The growing interest towards organic aquaculture and the presence of numerous private regulations led the European Union to face the problem and to introduce detailed production rules for organic aquaculture as part of the EU organic regulation in the first half of 2009: Commission Regulation (EC) N. 710/2009 amending Regulation (EC) No 889/2008 laying down detailed rules for the implementation of Council Regulation (EC) No 834/2007, as regards laying down detailed rules on organic aquaculture animal and seaweed production. The new Regulation, applied from July $1^{\text {st }} 2010$, introduces the general rules for producing, labeling and controlling algae and aquatic animals, and defines sustainable practices of breeding, feeding and the allowed veterinary treatment. Finally, particular attention has been given to animal welfare during the rearing phase.

However, different problems affect organic aquaculture and
Regulation 710/2009 can be at the moment only a starting point. Among those, is worth mentioning the issue of feed source and quality. Feedstuffs should come from organic food and/or sustainable fisheries or derive from trimmings of fish. This becomes a critical aspect for carnivorous species that use feed with high doses of flour and fish oils. The solution is not easy.

Despite the deficiencies in the legislative frame, in the last years, the organic aquaculture sector has widely expanded. Indeed, in 2009, it was present in 29 countries and counted 240 certified organic aquaculture production units (including microalgae production). Most of the production units are located in Europe and Asia. In Europe, the main product from organic aquaculture is the Atlantic salmon, followed by trout, carp, sea bass and sea bream. In Asia, the most commonly bred species is carp in monoculture or in combination with crab, shrimp and other species. In Latin American countries, such as Ecuador, Peru and Brazil, there is a strong predominance of western white shrimp farms.

The increased interest in organic aquaculture has led, of course, to an increased production that has reached 53,500 tons in 2009. This amount, remarkable in absolute terms, is still modest $(0.1 \%)$ if compared to the global aquaculture production that amounted in the same year to more than 55 million tons. However, even if at present it is a niche production, further growth of organic aquaculture is foreseeable, both thanks to the expansion of the already existing production units, and to new production initiatives.

Based on forecasts and estimates, the production deriving from organic aquaculture is going to increase in the future years at a rate of $20 \%$ per year between 2010 and 2020 , and at a rate of $10 \%$ per year between 2020 and 2030. It has been estimated, in fact, that the total production of this sector will increase by 240 -fold from $5000 \mathrm{t}$ in 2000 to 1.2 million tons in 2030 .

These forecasts may seem optimistic. Nonetheless, if one considers the growing awareness of consumers towards health and food quality, animal welfare and environmental impact even resulting from different promotional campaigns raising interest for agricultural organic production systems, it is reasonable to argue that in the near future organic aquaculture will conquer a respectable space within aquaculture productions.

${ }^{*}$ Corresponding author: Dr. Antonino Nizza, Department of Animal Science and Food Control ,University of Naples Federico II, Italy, Tel. +39 081 2536061; E-mail: nizza@unina.it

Received November 19, 2012; Accepted November 20, 2012; Published November 30, 2012

Citation: Nizza A (2012) What Future for Organic Aquaculture? J Aquacult Res Dev 3:e103 doi:10.4172/2155-9546.1000e103

Copyright: (c) 2012 Nizza A. This is an open-access article distributed under the terms of the Creative Commons Attribution License, which permits unrestricted use, distribution, and reproduction in any medium, provided the original author and source are credited. 